\title{
THE MENTAL SYMPTOMS OF MULTIPLE SCLEROSIS *
}

SANGER BROWN II, M.D., AND THOMAS K. DAVIS, M.D. NEW YORK

The mental symptoms of multiple sclerosis are of several types, and different writers stress different symptoms. Some describe the euphoric cases, others cases accompanied by dementia, while still others center their attention on the occasional episodes of depression, the delusions and hallucinations. A cursory view of the subject shows that in multiple sclerosis there is not a consistent group of symptoms.

We are quite unprepared to state the incidence of mental symptoms in multiple sclerosis. However, including euphoria, probably in 90 per cent. of cases there are mental alterations which warrant the term "mental symptoms." Because they are overshadowed by physical symptoms and are so often of a character to introduce no element of alarm, they are frequently disregarded. Then, too, the physical condition makes the patient inapt in all his physical undertakings and renders him psychiatrically nonpotential, even in those instances in which unhampered psychotic tendencies would otherwise bring different results. Generally speaking, the patient with multiple sclerosis cannot carry out the things which might lead to committment. Hence it is not surprising that there were only three cases of multiple sclerosis among the 6,700 insane patients in the Manhattan State Hospital.

We have not been able to demonstrate any predisposition to mental disease in these patients; the mental symptoms seem more dependent on the organic brain disease than on an underlying tendency.

\section{EUPHORIA}

Many patients with multiple sclerosis have a slight elevation of mood which may be termed euphoria. Although suffering from a serious disease, they do not think of their condition as serious, nor do they seem deeply concerned about it. In the great majority of cases it does not amount to a psychosis; it is simply a marked inconsistency between the patient's mood and his physical disability. The following case is illustrative:

A woman, 31 years of age, has had symptoms of multiple sclerosis for over ten years and has been in the Montefiore Home for three years. The case is an advanced one. She cannot walk; is nearly blind; her speech is so indistinct that she can scarcely make herself understood; she is so ataxic that she has

* Read before the Association for Research in Nervous and Mental Diseases, Dec. 29, 1921. 
to be fed. Despite the almost complete helplessness, she is optimistic and cheerful, laughs and jokes about her symptoms and is not in the least concerned about her condition. Neither is she demented. She can give a full and accurate account of her past life. This euphoria is the only mental symptom.

If euphoria were seen in only one case it might be regarded as individual, depending on the personality of the patient. But it is so frequent that it must be regarded as a mental change associated with multiple sclerosis. It was seen in ten of the fourteen patients showing mental symptoms whom we examined. The euphoria may become much more marked; a manic-like state may result.

Patients in a few cases described in the literature had delusions of grandeur similar to those seen in patients with paresis. This generally occurs as a terminal state associated with considerable dementia. But even these terminal cases do not, as a rule, show the silly euphoria nor the marked change in personality of the paretic. The cause of the euphoric state in multiple sclerosis is not known. The euphoria of paresis and the facetiousness often noted in brain tumor are also not clearly explained.

STATES OF MENTAL DEPRESSION

Patients with multiple sclerosis have developed suicidal ideas and have attempted suicide. We give an illustrative case:

In a man, aged 28 , symptoms were noted four years ago. When he became incapacitated because of his disease he became depressed and attempted to commit suicide with a razor. He was sent to Bellevue Hospital and then to Ward's Island, where he gradually grew worse and was tube-fed over a long period. He attacked other patients without provocation. At present he is irritable, but has grown somewhat euphoric. Although bedridden he thinks he could earn his own way if he left the hospital. His judgment is very poor, but no defects of memory can be determined.

This depressed type of mental disturbance is occasionally seen in multiple sclerosis, but in our experience it is not accompanied by great slowing or retardation. It is probably a mental reaction to the serious condition in which patients find themselves; but even in these cases euphoria tends to develop as the disease progresses.

\section{MENTAL DETERIORATION}

It might be expected that in a progressive organic brain disease such as multiple sclerosis, marked mental deterioration would occur in all patients. This is not the case. Often even in advanced cases, changes of this character are slight or amount only to a chronic mental tension defect. On the other hand, occasionally serious deterioration is seen. 
A patient in the Manhattan State Hospital is feeble, partially bedridden, and has greatly impaired vision. His memory is defective. Although he sees the physician from time to time he never recognizes him as the same man and once he thought that the physician was a relative. He cannot distinguish dinner from supper or recall when he has had his meals and when he has not. His judgment is very poor, and he says that he is staying in the hospital to kill time. His mood is one of unnatural complacency. Before he was committed to the hospital he spoke of hearing women's voices talking to him on the street. He imagined that there was some plot against him though he was not insistent about it and when mental deterioration began this trend disappeared.

His family history is so remarkable and so unlike that usually found in multiple sclerosis that it needs special comment. His brother died at the age of 31 of multiple sclerosis with mental symptoms. The diagnosis was confirmed at necropsy. His sister is now in the Central Islip State Hospital, with a case diagnosed as multiple sclerosis, and she also has a psychosis.

Deterioration, in brief, may or may not occur, though probably it is present in a majority of all cases; its degree of progress varies in different patients, only occasionally becoming profound; and as would be expected, as it develops it obliterates, to a large degree, tendencies which may have been present. Some patients have only a mild disturbance of memory, of which they are entirely aware. In a few reported cases there have been Korsakoff-like pictures, but we have found no such cases and feel that this type is rare.

\section{HALLUCINATIONS}

Auditory hallucinations without insight and occurring as a feature of a delusional trend are not unusual. The case mentioned in the foregoing is a typical instance of this.

We have to report a single example of considerably more bizarre hallucinatory phenomena in a case observed at the Neurological Institute :

A young woman, 31 years of age, whose physical symptoms have existed for two and one-half years, for many months has had visual hallucinations: To her the rug appears to be on fire and smoke issues from the carpet. She has seemed to see bright green beetles crawling on the window-pane. Occasionally she has seen people approach the door and she has not known definitely, until reassured, that no one was there. The remarkable feature is that she has perfect insight into these experiences. She cannot be said to be suffering from a psychosis, and she realizes that these false impressions are caused by her disease.

On one or two occasions she has had hallucinations of hearing, such as a band playing or voices singing. There are no hallucinations of taste, touch or smell. Examination of the eyes revealed 20/50 vision in the right eye; $20 / 70$ in the left eye, with temporal pallor of the optic disks and some contraction of the visual fields. 
The character of the hallucinations suggests that they arise on some irritative or toxic basis either in the higher visual centers or in the pathways leading to them.

\section{TRENDS}

Cases are occasionally seen which bear a certain resemblance to dementia praecox, of which the following is an example:

In a woman, aged 35 years, severe mental symptoms began after the disease had existed for nine years. Although she was entirely blind at that time, she thought that people were watching her, that they came into her room at night, and that they were threatening to kill her. She spoke of hearing voices. Much of her thought content had to do with sex affairs. She thought that men were paying her attention with the idea of marriage.

Although bedridden and entirely helpless she still talks about the possibility of marriage. However, these paranoid trends have almost entirely disappeared, and now she is mildly euphoric or at least contented and happy.

In this case the delusional trend and hallucinations may be less directly dependent on an organic lesion and appear to be of a more dementia-praecox-like nature. In none of our cases have we found negativistic phenomena or catatonic reactions.

\section{PERSONALITY}

Apart from certain mood changes, for example euphoria, patients with multiple sclerosis usually retain the same personality that they had before their illness. Even though there is deterioration, they do not as a rule show marked moral and ethical changes, and there is comparatively little of the grave disturbance of personality common in paresis. In this domain it is reported that those cases have resembled paresis most which at necropsy showed considerable lesions of the frontal lobes. However, even in such cases, personality changes were not great.

Careless use of terms has led some writers to talk of hysterical and neurasthenic reactions in the disease. We are struck by the absence of such features in the cases which we have studied.

\section{COURSE OF MENTAL SYMPTOMS}

An interesting characteristic of the mental symptoms in multiple sclerosis is their marked tendency toward change and tendency toward regression of certain of the phases, particularly the trends. Often the paranoid and delusional states are of only a few months' duration. The brevity of these states may be quite unexplainable. They may disappear as deterioration advances. With the subsidence of trends, there is a tendency for euphoria to increase, and grandiose elaboration may be a very late development. 


\section{CONCLUSIONS}

Our observations lead us to divide the mental symptoms of multiple sclerosis into two groups: first, those which are primary and directly the result of the organic lesions; second, those which are incidental and secondary.

In the first group we would place euphoria, since it seems to be associated with the organic brain condition; likewise the mental defect symptoms, the occasional hallucinations of organic origin and the very rare confused states and Korsakoff's psychosis; also the occasional terminal states with delusions of grandeur.

In the second group we would place those transitory delusional states and depressions which appear to arise as a result of the condition of incapacity in which the patient finds himself. Here probably belong suicidal attempts and delusional trends accompanied by hallucinations often of only a few months' duration. There are still other delusional trends which are more like dementia praecox. However, marked distortion of thought and oddities of conduct which are so frequent in dementia praecox are not encountered in multiple sclerosis.

While multiple sclerosis has symptoms in common with other organic brain diseases, the mental symptoms do not closely resemble these conditions. The clinical picture is not that of paresis nor that of cerebral arteriosclerosis. The symptoms are more like those occasionally seen in brain tumor.

There is no correlation between the parts of the body showing the effects of the disease in greatest intensity and the content of delusional or hallucinatory trends.

It is reasonable to suppose that the secondary symptoms, such as depressed and paranoid states, depend to a considerable extent on the mental makeup of the patient before the disease developed; but with the primary mental symptoms of the disease this is not the case. Although the latter are quite variable, they are not more so than are the physical symptoms.

\section{BIBLIOGRAPHY}

Bassoe, P.: Report of a Case of Multiple Sclerosis with a Delusional State and Terminal Delirium. Necropsy, J. Nerv. \& Ment. Dis. 45:268-269, 1917.

Bechterew, W.: Ueber die Läsion der Hirnrinde bei der disseminirten Sklerose, Neurol. Centralbl. 21:285, 1902.

Bourneville: Sclérose en plaques ayant debuté dans l'enfance; imbecilité, Progrès méd., Ser. 3, 11-12:321-328, 1900.

Dannenberger: Zur Lehre von den Geistesstörungen bei multipler Sklerose, Inaug.-Diss., Giessen, 1901.

Dercum, F. X.: A Case of Multiple Spinal Sclerosis Presenting Unusual Symptoms Suggesting Paresis, J. A. M. A. 59:1612-1613 (Nov. 2) 1912.

Euziere: Les troubles psychiques dans la sclérose en plaques, Arch. gén. de Méd., 1909, pp. 746-756. 
Freund, C. S.: Psychische Störungen bei multipler Sklerose, Berl. klin. Wchnschr. 50:1777-1778, 1913.

Gill, A. W.: Disseminated Sclerosis with Hysterical Symptoms of Seven Months' Duration; Symptoms Cured by Psychotherapy, Seale Hayne Neurol. Stud. 1:277 (Aug.) _1919.

Hunt, J. R.: Multiple Sclerosis with Dementia. A Contribution to the Combination Form of Multiple Sclerosis and Dementia Paralytica, Am. J. M. Sc. 126:974-985, 1903.

Kaplan, J. F.: Multiple Sclerosis with Psychical Signs, J. Nerv. \& Ment. Dis. 31:139-140, 1904.

Knoblauch, A.: Ein Fall von multipler Sklerose compliziert durch eine chronische Geistesstörung, Monatschr. f. Psychiat. u. Neurol. 24:238-250, 1908.

Lannois, M.: Troubles psychiques dans un cas de sclérose en plaques, Rev. Neurol. 11:876-881, 1903.

Maloney, W. J.: Disseminated Sclerosis, Proc. Roy. Soc. Med., Lond., Sect. Neurol. 3:99, 1909-1910.

Nonne, M.: Klinischer und anatomischer Beitrag zur Kasuistik der Geistesstörung bei multipler Sklerose, Mitteil. a. d. Hamburg. Staats. Krank. 11 : $199-212,1910$.

Nonne, M., et al.: Anatomische Untersuchung eines Falles von multipler Sklerose mit psychischen Störungen, Neurol. Centralbl. 29:842-845, 1910.

Pitres, A., and Marchand, L.: Observations de syndromes commotionels simulant des affections organiques du systeme nerveux central, Rev. neurol. 23 :298-311, 1916.

Raymond and Touchard: Sclérose en plaques debutant par des troubles mentaux simulant la paralyse generale, Rev. neurol. 17:224-228, 1909.

Redlich, E., and Economo, C.: Demonstration mikroskopischer Präparate eines Falles von multipler Sklerose mit psychose, Jahrb. f. Psychiat. 30: 315-318, 1909.

Ross, D. M.: The Mental Symptoms in Disseminated Sclerosis, Rev. neurol. \& Psychiat. 13: No. 8, 1917.

Schultze, F.: Ueber die beziehungen der multiplen Sklerose des centralen Nervensystems zur allgemeinen progressiven Paralyse der Irren, Arch. f. Psychiat. 11:216-229, 1881.

Seiffer: Ueber psychiche in besondere Intelligenzstörungen bei multipler Sklerose, Arch. f. Psychiat. 40:253, 1905.

Uyematsu, S.: A Case of Diffuse Cerebrospinal Sclerosis, J. Nerv. \& Ment. Dis. 51: $514-533,1920$.

Westphal, A.: Multiple Sklerose und Hysterie, Deutsch. med. Wchnschr. 32: 403, 1906. 